\title{
A Profile of Emergency Departments in Slovenia
}

\author{
Blanka Jaklic, ${ }^{1}$ Leana S. Wen, ${ }^{2}$ Ashley F. Sullivan, ${ }^{1}$ and Carlos A. Camargo Jr. ${ }^{1}$ \\ ${ }^{1}$ Department of Emergency Medicine, Massachusetts General Hospital, 326 Cambridge Street, Suite 410, Boston, MA 02114, USA \\ ${ }^{2}$ Harvard Affiliated Emergency Medicine Residency, Department of Emergency Medicine, Brigham and Women's \\ Hospital/Massachusetts General Hospital, 178 Marlborough Street, No. 5, Boston, MA 02116, USA \\ Correspondence should be addressed to Carlos A. Camargo Jr., ccamargo@partners.org
}

Received 9 May 2012; Accepted 30 May 2012

Academic Editors: A. Banerjee, E. De Guise, and A. Eisenman

Copyright ( 2012 Blanka Jaklic et al. This is an open access article distributed under the Creative Commons Attribution License, which permits unrestricted use, distribution, and reproduction in any medium, provided the original work is properly cited.

\begin{abstract}
Objectives. Emergency departments (EDs) are the basic unit of emergency medicine (EM), but there is often significant heterogeneity and differences in ED organization. We sought to describe and characterize EDs in Slovenia. Methods. All EDs open 24/7 to the general public were surveyed using the National ED Inventories survey instrument. Staff were asked about ED characteristics with reference to calendar year 2007. Results. Fifty-five EDs participated (81\% response). All EDs treated children and adults. Eleven $(20 \%)$ of the EDs were hospital based and $44(80 \%)$ were non-hospital based. The median number of annual visits for hospital-based EDs was 21,400 (interquartile range, 19,900-34,200) and 5,000 (interquartile range, 1,100-9,300) for nonhospital-based EDs. All hospital-based EDs had triage to service, and only one was an independent department. Most respondents (76\%, 95\% CI 64-89\%) thought their ED was at good balance or capacity. While hospital-based EDs had high availability of technological resources and ability to treat virtually all emergency types $24 / 7$, these characteristics were less frequent in nonhospital-based EDs. Conclusions. The organization of emergency care in Slovenia is complex, with some variation in the layout, characteristics, and capabilities of its EDs. This initial study establishes a benchmark for future investigations into intra-country comparisons of different types of EDs.
\end{abstract}

\section{Introduction}

Emergency medicine (EM) has been developing around the world $[1,2]$. While studies have focused on assessing overall systems of emergency care, there has been limited research on describing existing emergency departments (ED) internationally [3]. Examination of EDs in diverse settings could provide useful comparisons and additional insight into optimal approaches to provide emergency care.

The Republic of Slovenia, formerly a constituent component of Yugoslavia, declared independence in 1991. Its economic progression has been rapid such that Slovenia, with its population of 2 million, is now rated as a developed country with the highest gross domestic product per capita of new members of the European Union [4, 5]. Healthcare accounts for $9 \%$ of total national expenditure, and includes universal health care coverage [6].

Slovenia has a complex system of emergency care delivery involving three levels of EDs that are both hospital based and non-hospital based. The first is at the level of primary health centres located in small towns throughout the country.
They are staffed by primary care physicians who provide basic ambulatory emergency care in addition to in-thefield emergency service and regular family practice. The second is at the level of primary health centres in regional capitals. These are generally located near hospitals or within them. Physicians are additionally trained in basic emergency stabilization and provide a higher level of emergency care within the ED and in the field. Part of the duty of these regional EDs is to send physician-staffed ambulances that treat patients in the field and transfer patients to the local $\mathrm{ED}$ or to hospitals if necessary. The third level is EDs based in larger, acute care hospitals. They are staffed by doctors who are specialists in fields other than emergency medicine and are periodically assigned to rotate through the ED. EDs at all three levels provide care 24/7. Patients can self-present to any level of ED, or be transferred to higher levels of care depending on complexity [7-10].

The need for an improved and better-organised emergency care in both the hospital and prehospital setting led to the introduction of emergency medicine as a specialty in 2007 [10]. A five-year training program is in place to train 


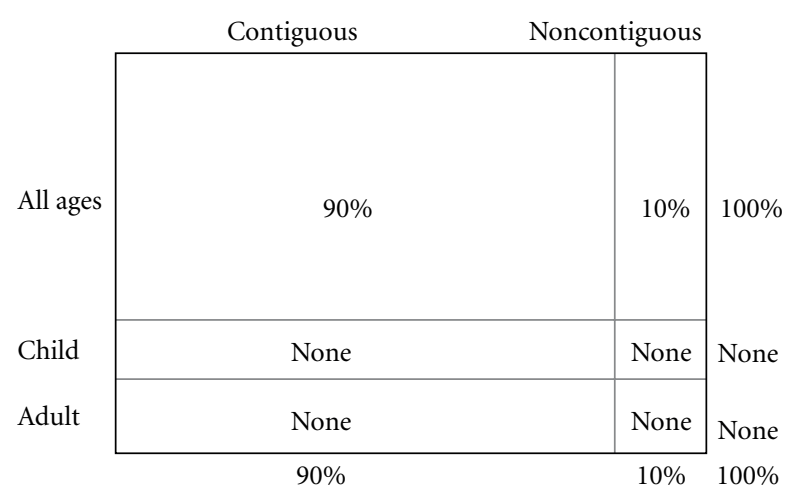

Total $=55 / 68$ EDs $(81 \%$ response $)$ Median annual visits $=6,100$ per ED $207 \mathrm{ED}$ visits per 1,000 population

FIgURE 1: Snapshot of overall ED characteristics in Slovenia.

specialist physicians with core skills necessary for optimal emergency care delivery within the ED, joining a small number of other countries in Eastern Europe that have nascent EM training programs $[11,12]$. Moreover, there is now a Slovenian Society for Emergency Medicine [13]. Still, the development of emergency medicine has many barriers to overcome, including the overall lack of human resources: a 2009 study of the healthcare workforce in Slovenia found that even in its capital, Ljubljana, there were only 2.3 doctors per 1,000 inhabitants [6].

To date, no study has sought to understand how EM is delivered in Slovenia at the level of the ED-the basic unit of EM. Given the expected complexity of emergency care, such an examination could be useful for better understanding EDs in Slovenia. Given the ongoing changes in Slovenia EM, this study can also be useful in establishing a benchmark for future comparisons. Finally, it can add to the burgeoning literature on ED organization internationally.

\section{Materials and Methods}

This was a cross-sectional descriptive study with web-based surveys administered to the ED physician administrator. Sites without Internet access were invited to participate using a paper survey. Consistent with terminology used in NEDIUSA, an ED was defined as an emergency care facility accessible to the general public that is open 24 hours per day, 7 days per week [12]. A list of EDs was created by the country coordinator and verified with data obtained from the Ministry of Health. All eligible EDs were invited to participate in the survey. The study was coordinated by the Emergency Medicine Network (EMNet) (http://www.emnetnedi.org/). This study was determined to be exempt by the institutional review board.

A 23-item questionnaire was employed. Data were collected in 2008-2009, and participants were asked about ED characteristics with reference to calendar year 2007. Survey questions were drawn, in part, from work done in thousands of us. EDs [14]. Survey design was agreed upon by four external consultants, all of whom were clinically active physicians in Slovenia. Questions were subdivided into four categories: ED characteristics, patient experiences in the ED, capacity, and resources and capabilities. Prior to implementation, survey questions were reviewed by members of the EMNet Steering Committee and several country coordinators. The survey has been used in four other countries to profile their EDs [15]. (Appendix 1, Supplementary Material available online at doi:10.5402/2012/461274).

Responses were directly downloaded from the EMNet website into an Excel spreadsheet (Microsoft Corp., Redmond, USA). Responses received were maintained on a secure, password-protected server. Descriptive statistics were calculated using Stata 11.0 (StataCorp, College Station, TX, USA).

\section{Results}

3.1. General Characteristics. Out of 68 EDs in Slovenia, 55 participated in the survey (81\%). Respondent and nonrespondent EDs $(n=13)$ did not differ with respect to ownership or metropolitan status. The majority of EDs (80\%) were non-hospital based (e.g., located in health centres). Ninety percent of EDs were contiguous with medical and surgical care provided in the same area. Thirty-nine percent of contiguous EDs used triage to service (e.g., triage of patients to a specific emergency service, e.g., medical versus surgical team); among hospital-based EDs $(n=11)$, every ED used triage to service. Only one of the hospital-based EDs surveyed was an independent department (2\%); the rest were under the auspices of the departments of internal medicine or surgery. The median number of annual visits for hospitalbased EDs was 21,400 (interquartile range, 19,900-34,200); the median was 5,000 (interquartile range, 1,100-9,300) for non-hospital-based EDs. All EDs treated both children and adults (Figure 1).

3.2. Patient Experiences in the ED. The majority of EDs reported that less than $20 \%$ of their patients arrived by ambulance. Length of stay was generally short, with $78 \%$ of EDs reporting patient length of stay less than 1 hour. Only $2 \%$ of EDs reported length of stay over 6 hours. There was variation in the percentage of ED visits leading to admission (Table 1).

3.3. Capacity. Most respondents (76\%, 95\% CI 64-89\%) thought their ED was at good balance or capacity, with $2 \%$ (95\% CI 0-6\%) responding that they were under capacity. Twenty-two percent (95\% CI 10-33\%) considered their ED to be overcapacity.

3.4. Resources and Capabilities. Although every ED in the survey met the criteria of being open to the general public 24 hours per day, 7 days per week, $18 \%$ of EDs were not staffed by physicians $24 / 7$. In $16 \%$ (95\% CI 6-26\%) of these EDs, physicians were available from within the hospital/health centre; in the remainder, the physician was available to be 
TABLE 1: Characteristics of EDs in Slovenia.

\begin{tabular}{|c|c|c|}
\hline & Proportion or median & 95\% Confidence interval or interquartile range \\
\hline \multicolumn{3}{|l|}{ General characteristics } \\
\hline Hospital based & $23 \%$ & $12-35 \%$ \\
\hline Independent department & $2 \%$ & $0-20 \%$ \\
\hline Contiguous & $90 \%$ & $83-100 \%$ \\
\hline Triage to service* & $39 \%$ & $14-64 \%$ \\
\hline Annual ED visits (median): hospital-based EDs & 21,400 & $19,900-34,200$ \\
\hline Annual ED visits (median): Non-hospital-based EDs & 5,000 & $1,100-9,300$ \\
\hline Annual ED visits (median): overall & 6,100 & $1,400-11,100$ \\
\hline \multicolumn{3}{|l|}{ Patient experiences in ED } \\
\hline \multicolumn{3}{|l|}{ Percentage of ED patients arriving by ambulance } \\
\hline$<20 \%$ & $67 \%$ & $45-89 \%$ \\
\hline $20-39 \%$ & $19 \%$ & $1-37 \%$ \\
\hline$>39 \%$ & $14 \%$ & $0-31 \%$ \\
\hline \multicolumn{3}{|l|}{ Length-of-stay } \\
\hline$<1$ hour & $78 \%$ & $67-89 \%$ \\
\hline $1-6$ hours & $20 \%$ & $9-31 \%$ \\
\hline$>6$ hours & $2 \%$ & $0-5 \%$ \\
\hline \multicolumn{3}{|l|}{ Percentage of ED visit leading to admission** } \\
\hline$<20 \%$ & $57 \%$ & $8-100 \%$ \\
\hline $20-39 \%$ & $0 \%$ & $0-50 \%$ \\
\hline $40-79 \%$ & $43 \%$ & 0-92\% \\
\hline$>80 \%$ & $0 \%$ & $0-14 \%$ \\
\hline \multicolumn{3}{|l|}{ Resources and capabilities } \\
\hline Physician in ED 24/7 & $82 \%$ & $81-92 \%$ \\
\hline Dedicated CT scanner & $18 \%$ & $8-29 \%$ \\
\hline Cardiac monitor & $98 \%$ & $94-100 \%$ \\
\hline Mechanical ventilator & $81 \%$ & $70-92 \%$ \\
\hline Respiratory isolation (negative-pressure room) & $0 \%$ & $0-14 \%$ \\
\hline Computer system to collect clinical data & $50 \%$ & $36-64 \%$ \\
\hline Internet access & $96 \%$ & $91-100 \%$ \\
\hline Clinical laboratory open round the clock & $24 \%$ & $12-35 \%$ \\
\hline
\end{tabular}

Abbreviations: ED: emergency department.

* among contiguous EDs only.

$* *$ There was low response to the question of ED visits leading to

admission. All other questions received $>90 \%$ response.

TABLE 2: Comparison of resources and capabilities of hospital-based to non-hospital-based EDs in Slovenia.

\begin{tabular}{lcc}
\hline Resources and capabilities & Hospital-based EDs $(n=11)$ & Non-hospital-based EDs $(n=44)$ \\
\hline Physician in ED or hospital 24/7 & $100 \%$ & $98 \%$ \\
Dedicated CT scanner & $100 \%$ & $0 \%$ \\
Cardiac monitor & $100 \%$ & $97 \%$ \\
Mechanical ventilator & $100 \%$ & $82 \%$ \\
Respiratory isolation (negative-pressure room) & $0 \%$ & $0 \%$ \\
Computer system to collect clinical data & $83 \%$ & $38 \%$ \\
Internet access & $83 \%$ & $100 \%$ \\
Clinical laboratory open round-the-clock & $100 \%$ & $0 \%$ \\
\hline
\end{tabular}

called in from outside the hospital/health centre. In all EDs, one physician is always on duty, though may not be physically present as a result of being called to interventions in the field.

There was significant variation in technological support. Whereas in hospital-based EDs, there were high levels of technological resources, non-hospital-based EDs had far lower numbers. For example, a dedicated CT scanner and clinical laboratory open around-the-clock were available in $100 \%$ of hospital-based EDs versus 0\% of non-hospitalbased EDs (Table 2). Non-hospital-based EDs also reported 
TABLE 3: Emergency types identified as treatable in surveyed EDs in Slovenia.

\begin{tabular}{|c|c|c|c|}
\hline Emergency type & Example of emergency & $\begin{array}{c}\text { Percentage of } \\
\text { hospital-based EDs able to } \\
\text { treat } 24 / 7(\%)\end{array}$ & $\begin{array}{c}\text { Percentage of } \\
\text { non-hospital-based EDs } \\
\text { able to treat } 24 / 7(\%)\end{array}$ \\
\hline Medical cardiology & Arrhythmia, acute myocardial infarction & $100 \%$ & $97 \%$ \\
\hline Medical oncology & Fever and neutropenia & $75 \%$ & $80 \%$ \\
\hline Medical other & Urinary tract infection, acute asthma & $100 \%$ & $97 \%$ \\
\hline Trauma & Motor vehicle crash, gun shot wound & $100 \%$ & $97 \%$ \\
\hline Neurological and neurosurgical & $\begin{array}{c}\text { Acute thromboembolic stroke, intracranial } \\
\text { haemorrhage }\end{array}$ & $100 \%$ & $94 \%$ \\
\hline Urological & Kidney stone & $100 \%$ & $97 \%$ \\
\hline Obstetrical & Complications of pregnancy & $100 \%$ & $90 \%$ \\
\hline Gynaecological & Ruptured ovarian cyst, yeast infection & $100 \%$ & $90 \%$ \\
\hline Ear, nose, throat & Severe epistaxis & $100 \%$ & $94 \%$ \\
\hline Ophthalmological & Acute glaucoma, eye injury & $100 \%$ & $93 \%$ \\
\hline Toxicological & Overdose, carbon monoxide poisoning & $100 \%$ & $96 \%$ \\
\hline Psychiatric & Psychosis & $100 \%$ & $90 \%$ \\
\hline Dental & Tooth extraction & $100 \%$ & $41 \%$ \\
\hline Surgical oral maxillofacial & Jaw fracture, oral abscess & $100 \%$ & $78 \%$ \\
\hline Surgical plastic & Severe lip laceration & $100 \%$ & $96 \%$ \\
\hline Surgical hand & Tendon injury & $100 \%$ & $92 \%$ \\
\hline Surgical orthopaedic & Long bone fractures & $100 \%$ & $96 \%$ \\
\hline Surgical general & Acute appendicitis, pneumothorax & $100 \%$ & $94 \%$ \\
\hline
\end{tabular}

Abbreviations: ED: emergency department.

fewer emergency types that were treatable 24/7, as compared to hospital-based EDs where virtually all emergencies were reported to be treatable $24 / 7$ (Table 3 ).

\section{Discussion}

Our survey results confirmed that the organization of emergency care in Slovenia is complex, with some variation in layout, characteristics, and capabilities of surveyed EDs. Perhaps the most striking difference among EDs is the high proportion of non-hospital-based EDs. This differs significantly from the us, the country where most of the data on ED profiling exists, and from preliminary data of other countries in our international survey [14-16].

A second striking finding in the study is the difference in resources and capabilities between hospital-based and non-hospital-based EDs. Whereas technological resources are widely available in hospital-based EDs, they are often lacking in non-hospital-based EDs. It is possible that lack of available technology is not a significant barrier to care since non-hospital- and hospital-based EDs are interdependent, and efficient transfer to hospital-based EDs is available and expected [7-9]. In fact, these non-hospital-based EDs exist in order to minimize ambulance response time in the field, and many patients are directly transferred from the field to hospital-based EDs [9].

What is more problematic is that while virtually all emergencies are identified to be treatable 24/7 in hospitalbased EDs, they are not in non-hospital-based EDs. Yet, all of the common emergencies surveyed are within the scope of a trained EM practitioner [15]. As Slovenia looks to improve emergency care, training of EM specialists with a core set of skills to address all common emergencies will be particularly important, especially in light of the rising doctor shortage in the country [17]. The presence of EM specialists may also help eliminate the concept of triage to service, since the EM specialist will be capable to see both medical and surgical (and other) emergencies. Future surveys will be useful to gauge the quality of emergency care, the frequency of transfers, and the comparison of models with and without triage to service as new EM-trained graduates begin to be placed at various EDs throughout the country. It will also be instructive to review the experiences of the first graduates from the EM training programme in Slovenia, particularly as compared to the standards set by the European Curriculum of Emergency Medicine [18].

Third, ED utilization in Slovenia is relatively low compared to the US, UK, and Australia, the countries with EM as a well-established specialty [19]. Based on a median of 6,100 overall ED visits, we estimate that there are approximately $207 \mathrm{ED}$ visits per year per 1,000 individuals. This is much lower than the same metric in the us, at 415 visits, for example. This lower rate of utilization is most likely attributed to the availability of universal primary care and a physician-level prehospital ambulance service and raises the question of whether there is a need to so many EDs with low visit volumes. One benefit of the multitude of smaller EDs is that they can maintain their higher throughput and remain at capacity or at good balance. Another benefit is faster and 
easier access to emergency service for all inhabitants in the country, particularly with the service of emergency care as physician-staffed ambulances. However, these benefits need to be balanced with the potential downside of smaller, nonhospital-based EDs lacking availability of technological and specialist resources. In addition, data are not yet available on how the parameter of ED visits is related to the physicianto-patient ratio, and how these parameters, in resourcerich countries, are associated with clinical outcomes [19]. An improved understanding of the degree of heterogeneity among countries will stimulate research into better resource utilisation around the world, in both the developed and developing world context.

The issue of $\mathrm{ED}$ utilization is related to the bigger question of what is the ideal system of emergency care. For example, is it best to have a large number of distributed, non-hospital-based EDs, or instead to have a small number of concentrated, high-volume, hospital-based EDs-or a system that has both? The large degree of variation within Slovenia offers the potential for intra- and inter-country comparisons of not just standard ED metrics such as capacity, capabilities, and resources, but also patient outcome data such as the quality and safety of emergency care.

4.1. Limitations. We recognize that this is an initial study with descriptive statistics, but it provides new information to guide efforts to characterise and advance emergency care in Slovenia. To our knowledge, a validated instrument to assess EDs worldwide does not exist. Questions from our survey have been used in the US [12] and several other countries $[15,16]$, ensuring usability and that the wording of questions was appropriate for diverse contexts.

This study was part of a multicountry survey of EDs [15]. The survey used is uniform, and only distinguished between hospital-based and non-hospital-based EDs. This distinction was adequate to describe other countries in our international survey, but does not encapsulate the complexity of the multilevel care of Slovenia EDs. Future studies can be useful in describing and characterising care using other metrics of distinction (e.g., three levels of ED care).

Another potential limitation is that this study relies on self-reported data. While exact figures would be ideal, the surveyed hospitals lack such record keeping, and the closest approximation is self-reports from ED physician administrators. Finally, the response rate was $81 \%$, with 13 EDs choosing not to participate in the study. If their experiences or responses differed markedly from those studied, this could introduce bias. The missing sites did not, however, differ in key parameters from the $>80 \%$ who did participate.

\section{Conclusion}

As efforts are underway to improve emergency care in Slovenia, our survey helps to establish a benchmark for documenting the complexity of Slovenia EDs. Future comparisons of systems with predominantly hospital-based EDs to those with a combination of non-hospital-based and hospitalbased EDs in particular can shed light on optimal systems of emergency care delivery, and whether it could be more efficient to preferentially train EM physicians to meet the country's emergency care needs. We hope that this initial study and other studies that follow will help to improve emergency care in Slovenia and other countries looking to restructure their emergency systems.

\section{Conflict of Interests}

The authors state that they have no disclosures or conflict of interests.

\section{Acknowledgments}

The authors would like to acknowledge all of respondents for their time in completing the surveys. The authors also would like to thank the following individuals for their advice regarding the design and implementation of the survey within Slovenia: Dr. Hugon Mozina, Dr. Andrej Zmavc, Professor Stefek Grmec, and Dr. Miloika Jutersek. The authors also wish to acknowledge Dr. Philip Anderson for his input into the design of the NEDI-International surveys. Dr. Jaklic and Dr. Wen are co-first authors of the publication.

\section{References}

[1] L. S. Wen, H. I. Geduld, J. T. Nagurney et al., "Africa's first emergency medicine training program at the University of Cape Town/Stellenbosch University: history, progress, and lessons learned," Academic Emergency Medicine, vol. 18, pp. 868-871, 2011.

[2] L. S. Wen, J. T. Nagurney, H. I. Geduld et al., “. Procedure competence versus number performed: a survey of emergency medicine specialists in a developing nation," Emergency Medicine Journal. In press.

[3] A. B. Steptoe, B. Corel, A. F. Sullivan et al., "Characterizing emergency departments to improve understanding of emergency care systems," International Journal of Emergency Medicine, vol. 4, pp. 42-50, 2011.

[4] International Monetary Fund, "Report for Selected Countries and Subjects," 2009, http://www.imf.org/.

[5] The World Bank, "World Development Indicators: Denmark," 2009, http://data.worldbank.org/indicator/.

[6] The World Health Organization, "Country brief," 2009, http://www.who.int/countries/svn/en/.

[7] World Health Organization, "Health Systems in Transition: Slovenia," 2009, http://www.who.int.

[8] Pravilnik o sluzbi nujne medicinske pomoci, "Uradni list RS, 3039, stran 7768, st. 57/2007," http://www.uradni list.si/1/objava.jsp?urlid=200757\&stevilka=3039.

[9] S. Grmec and A. Zmavc, "The models of organization of emergency medical services and specialty of emergency medicine in the world and in Slovenia. Acute conditions: signs, symptoms, syndromes, differential diagnosis and management," in Proceedings and Algorithms of the 3rd International Seminar on Acute Medicine, pp. 297-304, Maribor, Slovenia, 2007.

[10] A. Zmavc, "Organizacija predbolnisnicne sluzbe nujne medicinske pomoci v Sloveniji," in Strokovni Seminar Zivljensko Ogrozen Pacient-Nujnost Povezovanja, pp. 27-30, Terme Catez, Slovenia, 2005. 
[11] T. Fleischmann and G. Fulde, "Emergency medicine in modern Europe," Emergency Medicine Australasia, vol. 19, no. 4, pp. 300-302, 2007.

[12] N. Salihefendic, M. Zildzic, I. Masic, Z. Hadziahmetovic, and D. Vasic, "Development of emergency medicine as academic and distinct clinical discipline in Bosnia \& Herzegovina," Medicinski Arhiv, vol. 65, no. 1, pp. 46-51, 2011.

[13] Slovenian Society for Emergency Medicine, 2012, http://www. ssem-society.si/.

[14] A. F. Sullivan, I. B. Richman, C. J. Ahn et al., "A profile of US emergency departments in 2001," Annals of Emergency Medicine, vol. 48, no. 6, pp. 694-701, 2006.

[15] The Emergency Medicine Network (EMNet), "The National ED Inventories survey instrument,” 2011, http://www.emnetnedi.org.

[16] L. S. Wen, J. I. Oshiomogho, G. I. Eluwa et al., ". Characteristics and capabilities of emergency departments in Abuja, Nigeria," Emergency Medicine Journal. In press.

[17] International EM Core Curriculum and Education Committee for the International Federation for Emergency Medicine, "International Federation of Emergency Medicine model curriculum for emergency medicine specialists," Canadian Journal of Emergency Medical Care, vol. 13, no. 2, pp. 109-121, 2011.

[18] European Society for Emergency Medicine, "European Curriculum of Emergency Medicine," 2012, http://www.eusem. org/curriculumofem/.

[19] The World Bank, "World Development Indicators," 2011, http://data.worldbank.org/indicator. 


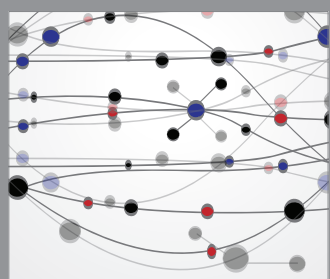

The Scientific World Journal
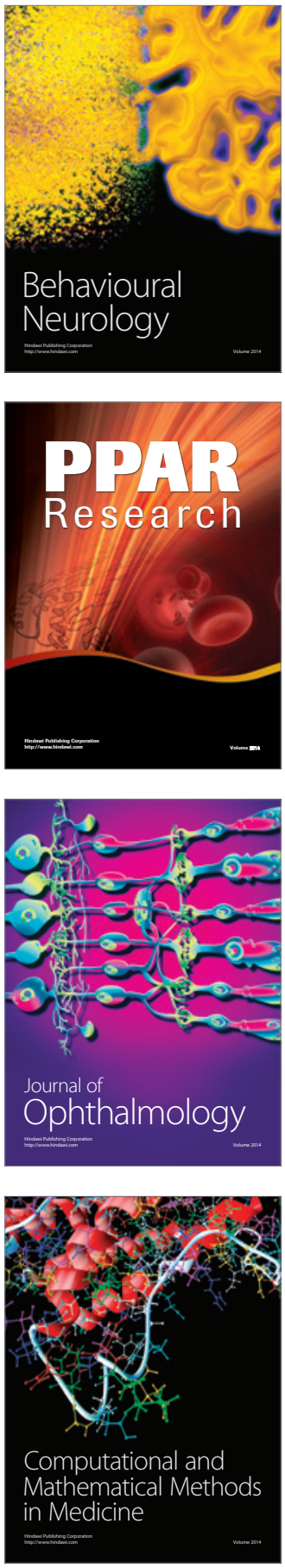

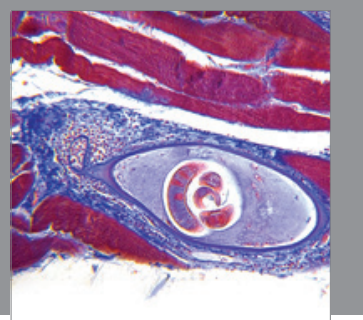

Gastroenterology

Research and Practice
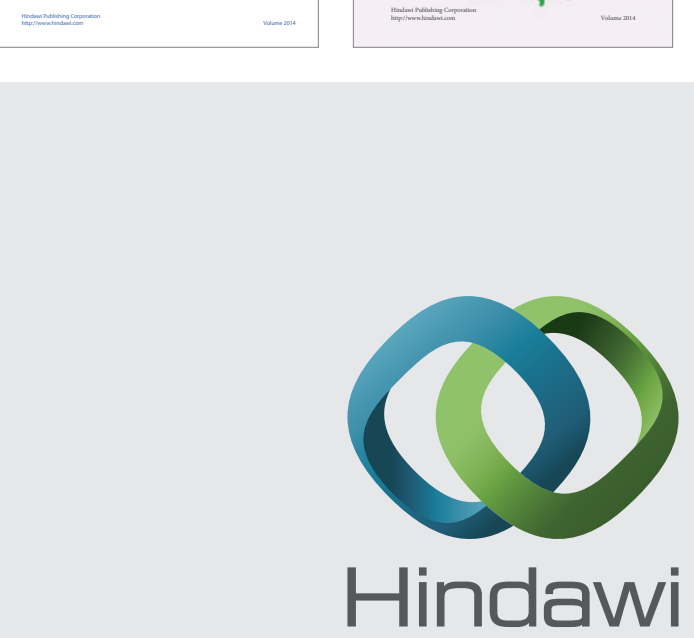

Submit your manuscripts at

http://www.hindawi.com
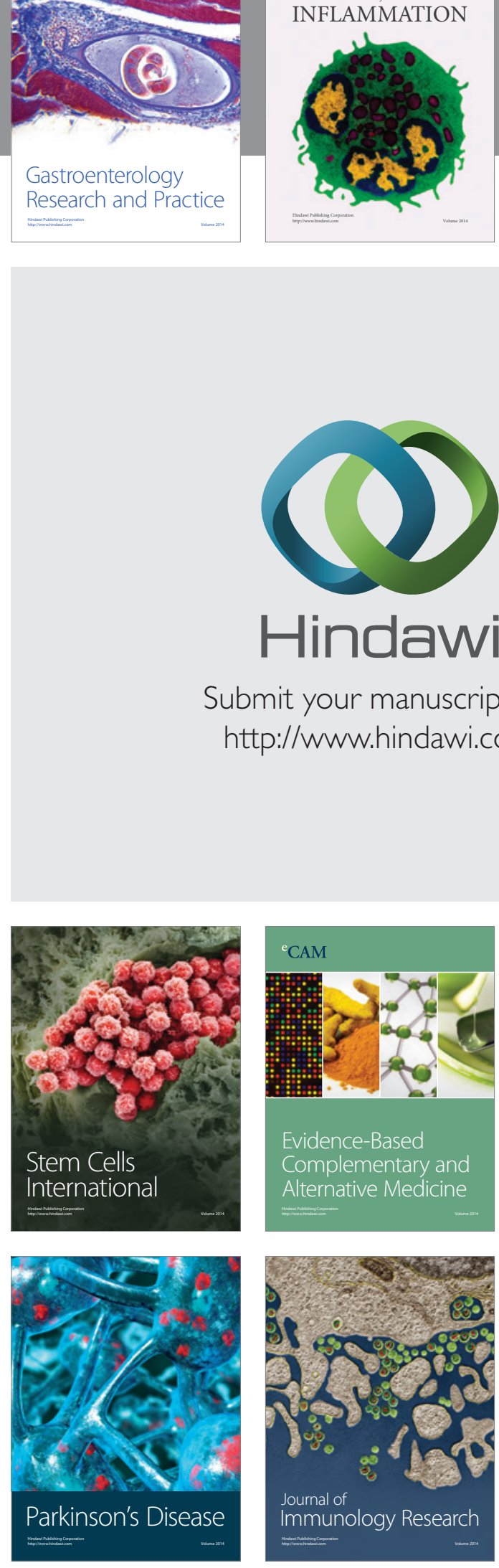

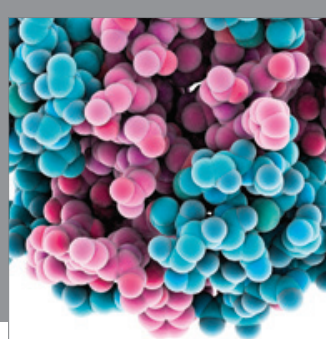

Diabetes Research
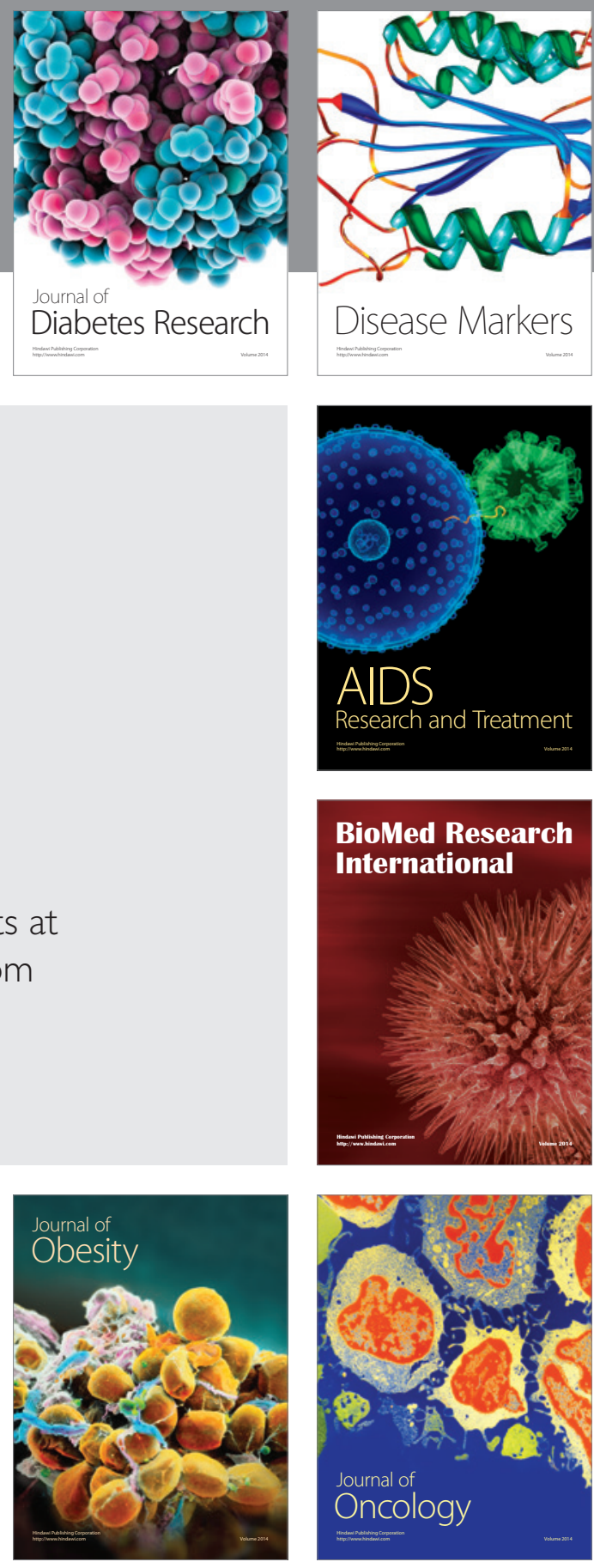

Disease Markers

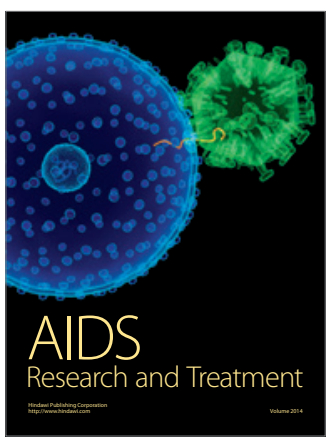

BioMed Research

International
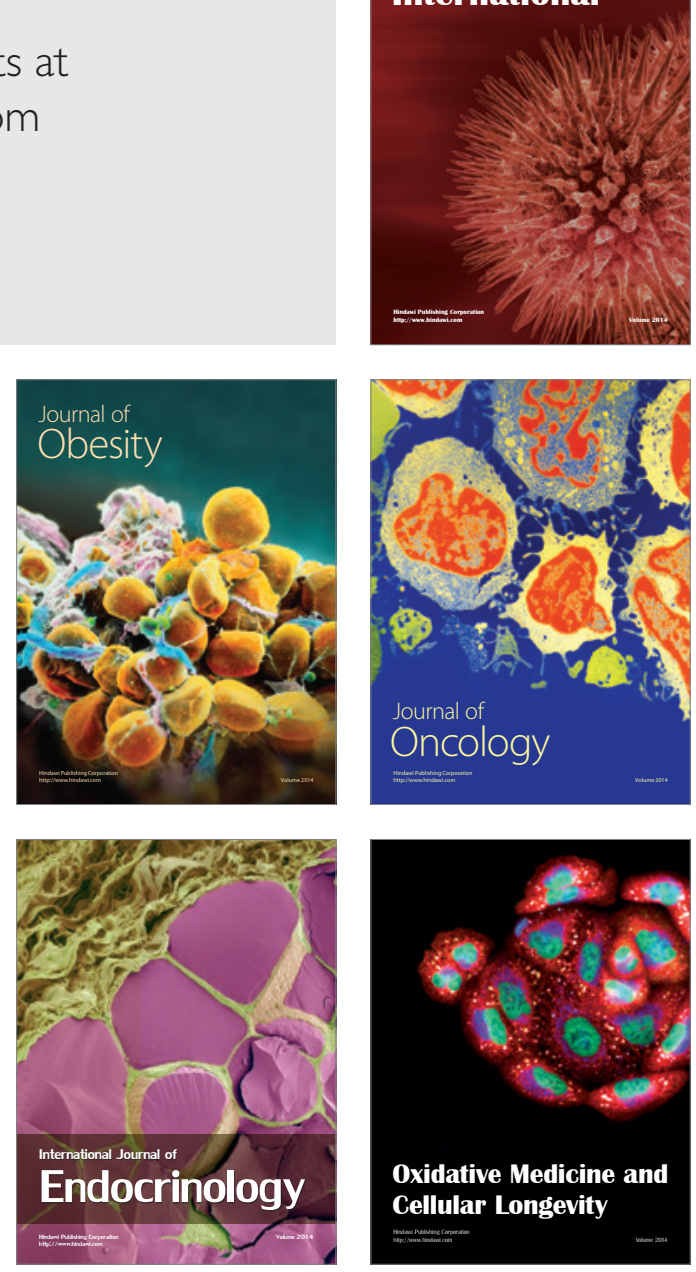